\title{
Uniform risk spectra for negative stiffness systems
}

\section{Conference Paper}

Author(s):

Reggiani Manzo, Natalia; Lachanas, Christos G.; Vassiliou, Michalis F.; Vamvatsikos, Dimitrios

Publication date:

2021-06

Permanent link:

https://doi.org/10.3929/ethz-b-000492004

Rights / license:

In Copyright - Non-Commercial Use Permitted

Funding acknowledgement:

ETH-10 18-1 - Seismic analysis, design and experimental testing of precast controlled-rocking negative-stiffness systems (ETHZ) 


\title{
UNIFORM RISK SPECTRA FOR NEGATIVE STIFFNESS SYSTEMS
}

\author{
Natalia Reggiani Manzo ${ }^{1}$, Christos G. Lachanas ${ }^{2}$, Michalis F. Vassiliou ${ }^{1}$, and \\ Dimitrios Vamvatsikos ${ }^{2}$ \\ ${ }^{1}$ ETH Zürich \\ Institute of Structural Engineering \\ Stefano-Franscini-Platz 5, 8093 Zürich, Switzerland \\ \{reggianimanzo,vassiliou\}@ibk.baug.ethz.ch \\ ${ }^{2}$ National Technical University of Athens \\ School of Civil Engineering \\ 9, Iroon Polytechniou str., Zografou Campus, GR-15780, Athens, Greece \\ \{lahanasch,divamva\}@central.ntua.gr
}

\begin{abstract}
This paper presents uniform risk spectra for negative stiffness systems that do not exhibit hysteretic damping, named Negative Stiffness Bilinear Elastic (NSBE) systems. The NSBE oscillator can be used to describe the dynamics of deformable rocking systems with or without restraining systems flexible enough to lead to an overall negative stiffness. It can also be used to describe rocking systems equipped with curved extensions at their base. It has been shown that the response of an NSBE system can be well predicted using the response of a Zero Stiffness Bilinear Elastic (ZSBE) system, which is a bilinear system of constant restoring force. The ZSBE system is a single parameter system; therefore it is simple to construct design spectra for it.

For a wide range of ZSBE system strength values, this paper employs Incremental Dynamic Analysis using 105 ordinary (non-pulse-like, non-long-duration) ground motions to obtain the fragility functions for predefined limit-states of the ZSBE seismic response. Fragility functions per limit-state are convolved with the seismic hazard to compute the Mean Annual Frequency of exceedance (MAF). For this study, the seismic hazard curve for a site at Athens Greece is used as it is obtained via probabilistic seismic hazard analysis. Finally, uniform risk spectra per limit-state are obtained by computing the MAF for all the ZSBE oscillators. These spectra can be used for the design of NSBE systems, including rocking oscillators.
\end{abstract}

Keywords: Uniform Risk Spectra, nonlinear dynamics, negative stiffness, rocking, rocking spectra 


\section{INTRODUCTION}

Rocking has been proposed as an alternative design method in seismic prone regions because it reduces foundation moments and results in resilient structures [1-19]. Differently from structures designed to yield, rocking systems present negative lateral stiffness after uplift.

The negative stiffness value of the free-standing block is defined by its geometry (Fig. 1). Its negative stiffness, however, can be modified by the introduction of restrainers flexible enough to keep the post-uplift stiffness negative (Fig. 2a) [3, 5, 13, 20-22], or by equipping the blocks with extended curved ends (Fig. 2b) $[14,15]$. These solutions increase the maximum displacement the rocking system can achieve before overturning, without affecting its uplifting force. The flexible restrainers also act as a redundant mechanism for the rocking structures, a desired mechanism by practicing engineers.

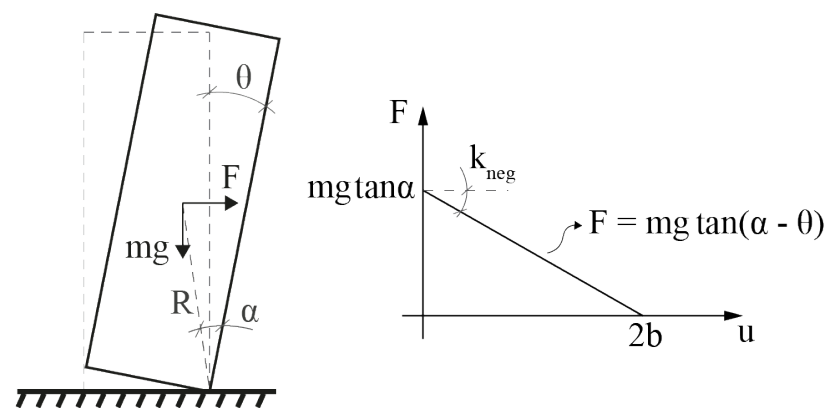

Figure 1. Free-standing rigid rocking block.

(a)

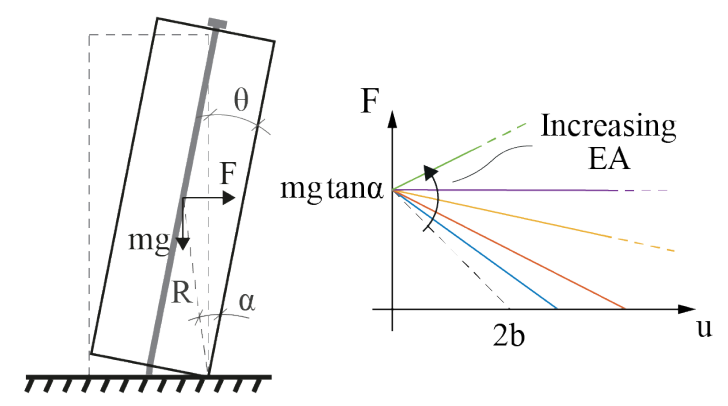

(b)

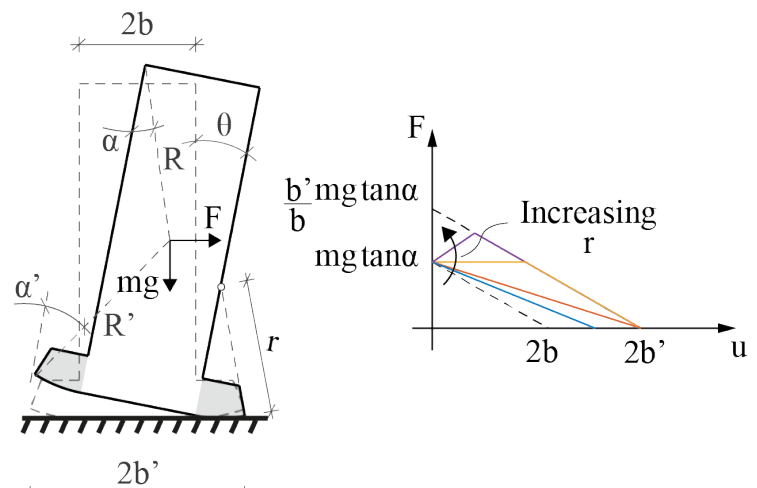

$2 b^{\prime}$

Figure 2. (a) Restrained rigid rocking block, and (b) Curved-base rigid rocking block.

Seismic codes adopt the uniform hazard spectrum concept. The spectrum is constructed using a probabilistic framework and provides seismic actions with a given probability of exceedance. Recently, Luco et al. [23] proposed the Uniform Risk Spectra (URS), which provides seismic actions that results in structures with uniform risk of damage and/or collapse, an indicator much more meaningful for decision makers and users of the designed structure.

Both the uniform hazard spectrum and uniform risk spectrum are useful tools that allow engineers to design structures by only estimating its fundamental period and damping ratio. The elastic spectra, however, cannot be used for designing rocking structures [24]. The inherent negative stiffness of rocking systems would oblige engineers to carry out time-consuming time history analyses when designing such structures.

Reggiani Manzo and Vassiliou [25, 26] have observed that rocking systems having the same uplift force and being far from their failure point will exhibit roughly equal displace- 
ment demand, independently of their post uplift stiffness. Therefore, the displacement of rocking structures of uplift force $f_{u p}$ can be computed using as a proxy the displacement of a bilinear oscillator of uplift force $f_{u p}$ and infinite displacement capacity (Zero Stiffness Bilinear Elastic (ZSBE) oscillators). This simplification allows the construction of spectra for a range of negative stiffness systems: free-standing rocking frames, restrained rocking frames, or rocking frames with curved ends. Therefore, the design of negative stiffness systems can be accomplished using a spectrum and avoiding time history analysis.

In an attempt to propose a simplified design methodology for negative stiffness systems that also introduces the uncertainty of seismic action, this paper presents uniform risk spectra for rocking structures, using the ZSBE oscillator proxy.

Previous studies have presented fragility curves for rocking structures [27-37], which also consider the random characteristic of seismic actions. Theses curves, however, were constructed using complex models, or in other cases, considering the classical description of the motion of rocking blocks by its tilt angle. Neither approach allows the construction of a single rocking spectrum that covers all range of systems with negative post-uplift stiffness. On the other hand, the uniform risk spectra proposed herein can be used for any system that presents negative post-uplift stiffness and does not present hysteretic damping.

\section{THE ZERO STIFFNESS BILINEAR ELASTIC SYSTEM (ZSBE) AS PROXY FOR NEGATIVE STIFFNESS BILINEAR ELASTIC SYSTEMS (NSBE)}

\subsection{The Negative Stiffness Bilinear Elastic System}

The Negative Stiffness Bilinear Elastic (NSBE) system can describe the dynamics of freestanding (Fig.1), restrained (Fig.2a), and curved-based (Fig.2b) rocking structures, or any other deformable system that presents negative post-uplift stiffness and does not exhibit hysteretic damping.

Fig.3 presents the NSBE oscillator, and its displacement-restoring force relationship. Up until uplift, the system behaves linearly with a positive stiffness $\left(k_{p o s}\right)$, representing any deformability the system might present before uplifting. After uplifting, the tangent stiffness becomes negative $\left(k_{n e g}\right)$. The displacement capacity $\left(u_{c a p}\right)$ is defined not by material failure, but by the displacement where the restoring force becomes negative. Therefore, for an unrestrained rocking column, the displacement capacity is equal to its width.

(a)

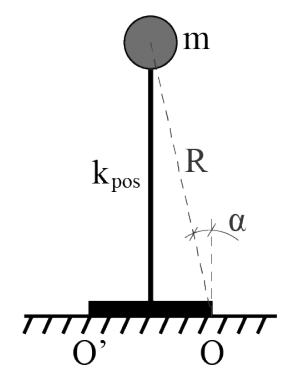

(b)

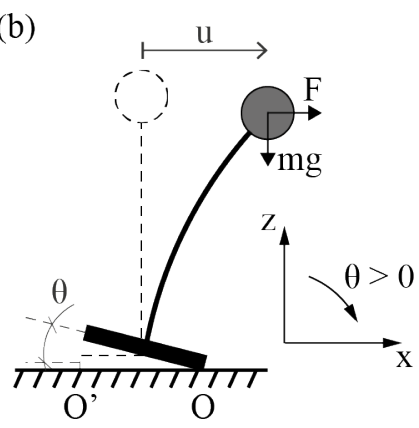

(c)

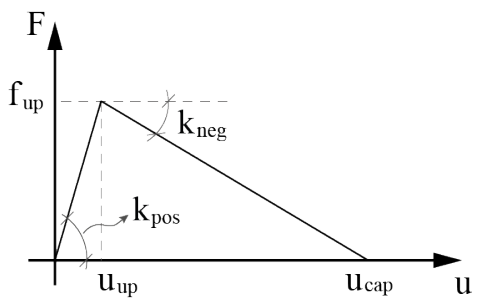

Figure 3. (a,b) NSBE system; and (c) its displacement-restoring force relationship.

Based on its displacement-force relationship (Fig.3c), the oscillator's equation of motion is:

$$
m \cdot \ddot{u}(t)+f_{u p} \cdot \frac{u(t)}{u_{u p}}=-m \cdot \ddot{u}_{g}(t),|u(t)| \leq u_{u p}
$$




$$
m \cdot \ddot{u}(t) \pm f_{u p} \cdot\left(\frac{u_{c a p}-u(t)}{u_{c a p}-u_{u p}}\right)=-m \cdot \ddot{u}_{g}(t),|u(t)|>u_{u p}
$$

The upper sign in Eq.2 corresponds to positive displacements, and the lower sign to negative displacements.

Impact damping is the only source of energy dissipation, implying that the ends of the rocking element are protected from damage [38]. When the system's displacement equals to the uplift displacement $\left(u_{u p}\right)$, the integration is halted, and its post-impact velocity is calculated by a coefficient of restitution $\left(r_{c}\right)$ :

$$
r_{c}=\frac{\dot{u}_{\text {postimpact }}}{\dot{u}_{\text {preimpact }}}
$$

Herein, a coefficient of restitution equal to 0.95 is assumed, corresponding to relatively slender structures.

\subsection{The Zero Stiffness Bilinear Elastic System}

Fig. 4 presents the displacement-force relationship of the Zero Stiffness Bilinear Elastic (ZSBE) system. The system presents the same equation of motion and assumptions of the NSBE system when its displacement capacity tends to infinity, resulting in a system with zero post-uplift stiffness $\left(k_{\text {neg }}=0\right)$.

The ZSBE can be used as a proxy for the prediction of the response of the NSBE $[25,26]$. Hence, studying the response of a ZSBE of a given $f_{u p}$ and $u_{u p}$ suffices for the description of the response of all NSBE of the same $f_{u p}$ and $u_{u p}$, independently of their $u_{c a p}$. Therefore, spectra providing $u_{\max }$ of the ZSBE as a function of $f_{u p}$ for a given $u_{u p}$ can be used for the design of NSBE systems. Fig. 5 presents such a spectrum, extracted from Reggiani Manzo and Vassiliou [26]. It refers to $u_{u p}=0.0005 \mathrm{~m}$ and it gives the median response for a set of ground motions selected and scaled as discussed in [26].

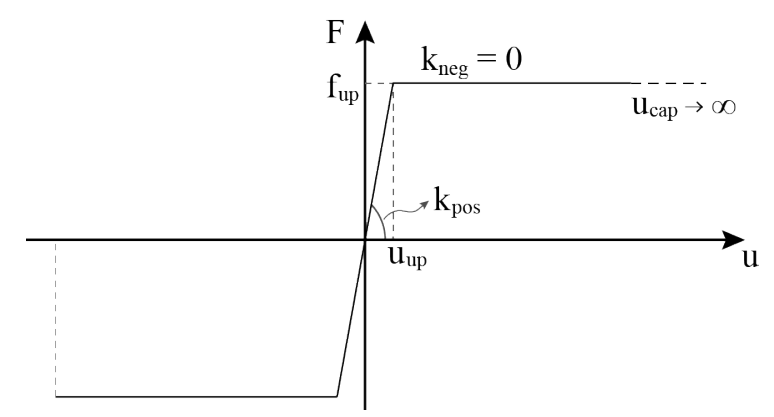

Figure 4. Displacement-restoring force relationship of the ZSBE systems.

\subsection{Equal Displacement and Equal Energy Rules for Negative Stiffness Systems}

Reggiani Manzo and Vassiliou [25, 26] proposed that the displacement demand of NSBE and ZSBE systems can be related by two different rules: the Equal Displacement rule and the Equal Energy rule.

The Equal Displacement rule assumes that the NSBE and ZSBE system will experience the same displacement demand (Fig. 6a):

$$
u_{d e m, N S}=u_{d e m, Z S} \rightarrow \gamma_{E D}=\frac{u_{d e m, N S}}{u_{d e m, Z S}}=1
$$




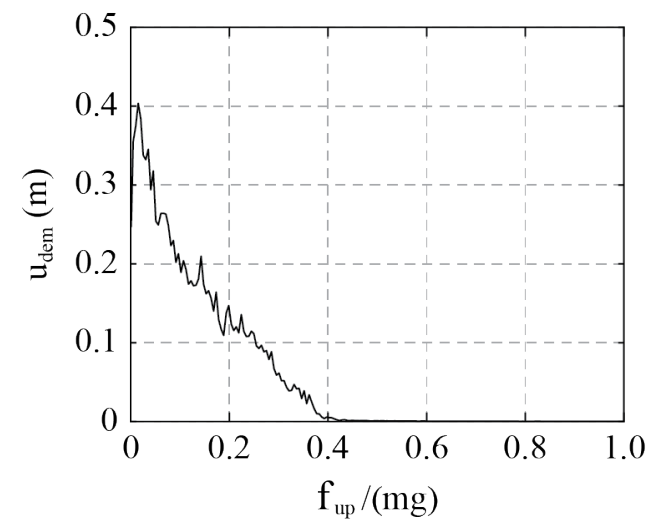

Figure 5. Design spectrum for negative stiffness systems.

In which, $\gamma_{E D}$ is the ratio of the displacement demand of the NSBE system $\left(u_{d e m, N S}\right)$ to the displacement demand of the ZSBE system $\left(u_{\text {dem,ZS }}\right)$.

The Equal Energy rule assumes that the displacement-force curves of both systems produce the same work. In other words, it assumes that the shaded areas of Fig. $6 \mathrm{~b}$ are equal. Therefore, the ratio $\left(\gamma_{E E}\right)$ of $u_{d e m, N S}$ to $u_{d e m, Z S}$ is:

$$
\gamma_{E E}=\frac{u_{d e m, N S}}{u_{d e m, Z S}}=\frac{u_{c a p}}{u_{d e m, Z S}}-\sqrt{\frac{\left(u_{c a p}-u_{u p}\right)}{u_{d e m, Z S}} \cdot \frac{\left(u_{c a p}-2 \cdot u_{d e m, Z S}+u_{u p}\right)}{u_{d e m, Z S}}}
$$

(a)

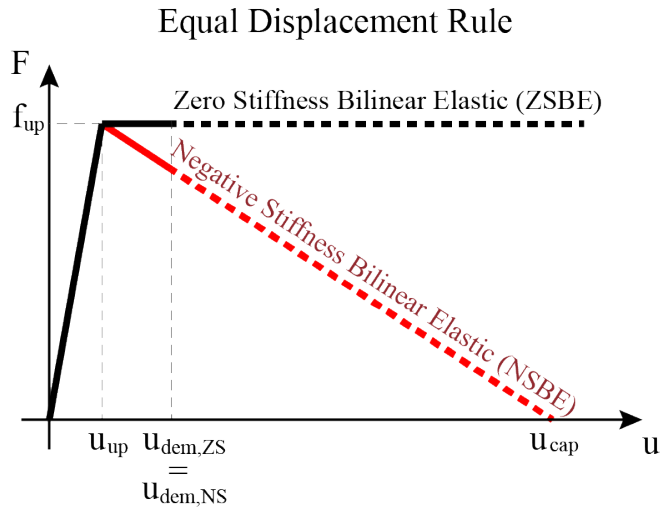

(b)

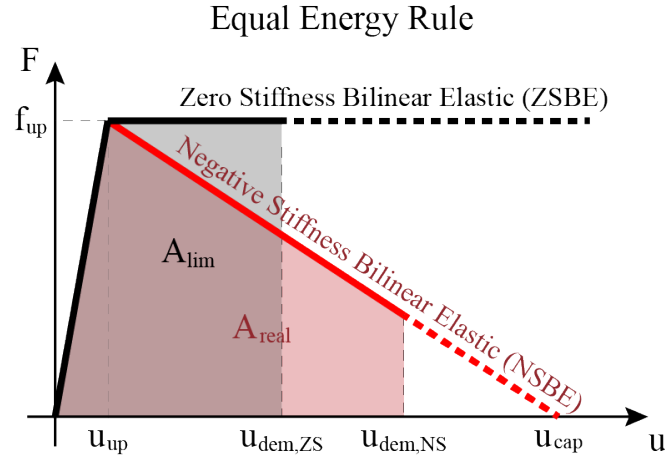

Figure 6. (a) Equal Displacement rule; and (b) Equal Energy rule.

\section{PROBABILISTIC FRAMEWORK}

Using the ZSBE proxy, the uniform risk spectrum for negative stiffness systems is a plot of the displacement demand of the system as a function of its normalized strength, in which all ordinates of the plot present the same mean annual frequency (MAF) of exceedance (Fig. 7b). It can also be interpreted as an iso-MAF contour plot of the seismic risk surface, which is a 3D plot of the probability of exceeding a displacement demand for a range of systems with different normalized strengths (Fig. 7a). 
(a)

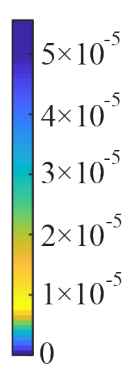

(b)

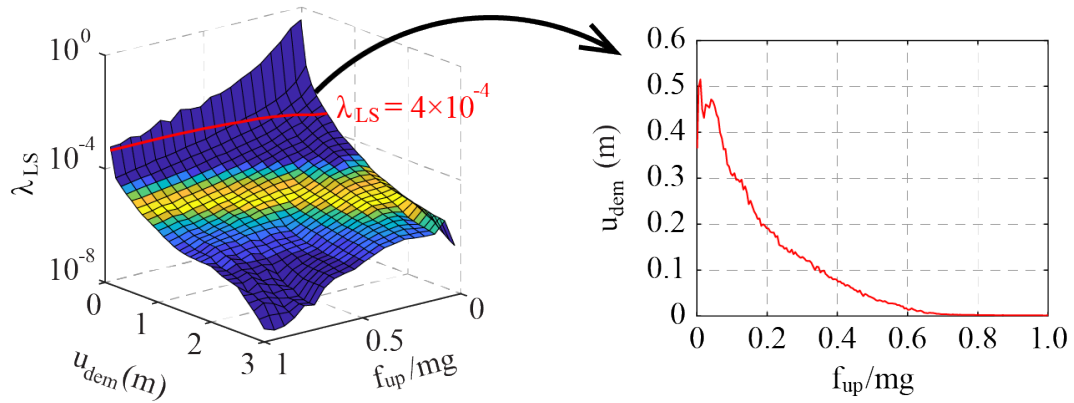

Figure 7. (a) Seismic risk surface with an iso-MAF contour plot highlighted; (b) Uniform risk spectrum.

The calculation of the probability of exceedance, also known as risk assessment, can be performed using the risk integral, the same framing equation of PBEE (Performance Based Earthquake Engineering) framework [39]:

$$
\lambda_{L S}=\lambda\left(E D P>E D P_{C}\right)=\int P\left(E D P>E D P_{C} \mid I M\right) \cdot|d \lambda(I M)|
$$

In Eq. $6, \lambda_{L S}$ is the mean annual frequency (MAF) of exceeding (i.e., violating) a limit state (LS). $P\left(E D P>E D P_{C} \mid I M\right)$ is the fragility function, which represents the probability that the engineering demand parameter $(E D P)$ exceeds the capacity threshold of $E D P_{C}$ associated with $L S$ for any given level of the ground motion intensity measure $(I M)$, and $\lambda(I M)$ is the MAF of exceeding a given value of $I M$, which can be retrieved from the site-specific seismic hazard curve.

In this paper, the maximum horizontal displacement of the system, or as mentioned before, the displacement demand, was adopted as EDP. Note that Eq.6 gives a single-point of the seismic risk surface. To construct the complete surface, the equation had to be evaluated for several limit states and a range of systems with different normalized uplifting strength. Herein, the probability of exceedance was calculated for 3001 limit states, ranging from 0 to $3 \mathrm{~m}$, in steps of $0.001 \mathrm{~m}$; and 301 different systems with a normalized strength varying from 0.1 to 1.0 , in steps of 0.05 .

Based on Eq.6, $\lambda_{L S}$ combines the structural response and the seismic hazard at the site. The fragility function, or vulnerability analysis, gives us information about the structural response of the system, connecting the $E D P$ to the $I M$. Given that all results are conditioned on the $I M$, the $I M$ has to be carefully chosen [40]. The adequate $I M$ for rocking structures, however, is still an open discussion in the engineering community [27-30, 36]. Herein, the peak ground velocity $(P G V)$ was adopted as $I M$, with further studies pending.

Incremental dynamic analyses (IDA) [41] were carried out to obtain the fragility functions for each predefined limit state and different system. A set of 105 ordinary (non-pulse-like, non-long-duration) ground motions was used in each incremental dynamic analysis. The ground motions were gradually scaled so that their $P G V$ is equal to $\overline{P G V}=[(1: 0.5: 20),(25: 5: 200)] \mathrm{cm} / \mathrm{s}$, in which $\overline{P G V}$ is the geometric mean of the $P G V$ of the two horizontal components $x$ and $y$ of the individual ground motion:

$$
\overline{P G V}=\sqrt{P G V_{x} \cdot P G V_{y}}
$$

The model considers only planar response. Therefore, the nonlinear dynamic analysis was carried out only for one of the components of each ground motion (arbitrary component); the component was once chosen randomly, and then used for all analyses. After carrying out the analyses for all different scales and ground motions, the fragility function for each limit state 
and system can be easily obtained on an EDP-basis or an IM-basis approach [40]. Here, the first was employed where for each IM-step value (stripe) the probability of exceeding the deterministic EDP capacity threshold is calculated as:

$$
P\left(E D P>E D P_{C} \mid I M\right)=\frac{\text { number of records with } E D P>E D P_{C}}{\text { total number of records }}
$$

The second curve necessary for the convolution represented by Eq.6 is the site-specific seismic hazard curve. In this study, a seismic hazard curve for a site at Athens, Greece was assessed via the open source platform OpenQuake [42]. The 2013 European seismic source model [43] was used for the calculations. The site-specific seismic hazard curve for the $\overline{P G V}$ is presented in Fig. 8.

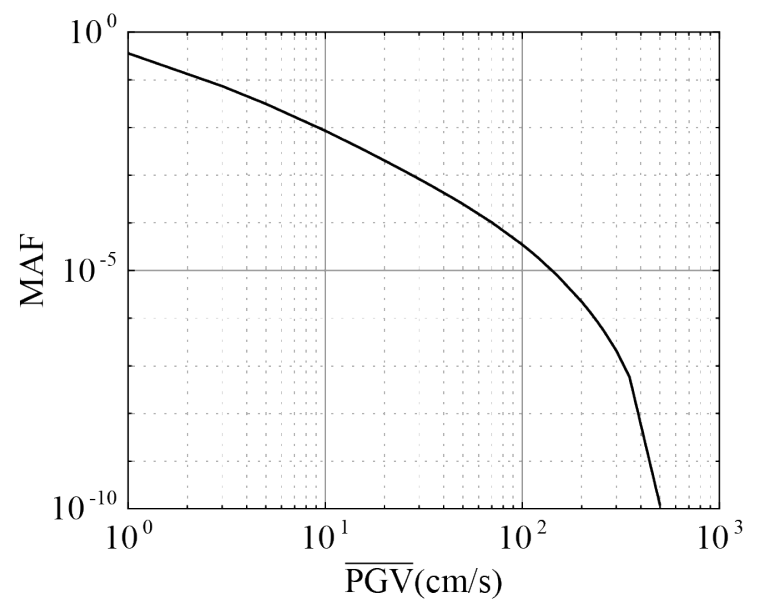

Figure 8. Site-specific seismic hazard curve for $\overline{P G V}$ in Athens, Greece.

At last, after carrying out the vulnerability analysis for all desired systems and limit states, the uniform risk spectrum for a given MAF can be obtained as a cross-section of the seismic risk surface.

\section{RISK ASSESSMENT}

Herein, uniform risk spectra for quasi-rigid ZSBE systems $\left(u_{u p}=0.0005 \mathrm{~m}\right)$, computed using the probabilistic framework of the previous section, is presented.

\subsection{Fragility Curves}

As the first step of the vulnerability analysis, fragility curves were computed for the different limit states and systems. As mentioned before, the ground motions were gradually scaled in stripes of $\overline{\mathrm{PGV}}=[(1: 0.5: 20),(25: 5: 200)] \mathrm{cm} / \mathrm{s}$. A finer discretization for smaller values of $\overline{\mathrm{PGV}}$ was necessary because low PGV ground motions might have small overturning potential, but they have large probability of occurrence resulting in significant contribution to the convolution of Equation 6.

Fig. 9 presents the fragility curve obtained using a coarse mesh (ranging from 1 to 100 $\mathrm{cm} / \mathrm{s}$, in steps of $5 \mathrm{~cm} / \mathrm{s}$ ) and using the finer mesh for a system with normalized strength $f_{u p} /(m g)=0.15$ and limit state of $9.0 \mathrm{~cm}$. Because the fragility curve is created by a linear interpolation between the values for which the probability was calculated, the coarse mesh cannot capture the peaks and troughs as accurately as the finer mesh. If the risk quantity is 
calculated using both fragility curves presented in Fig.9, the one with the coarse mesh overestimates the risk by $12 \%$.

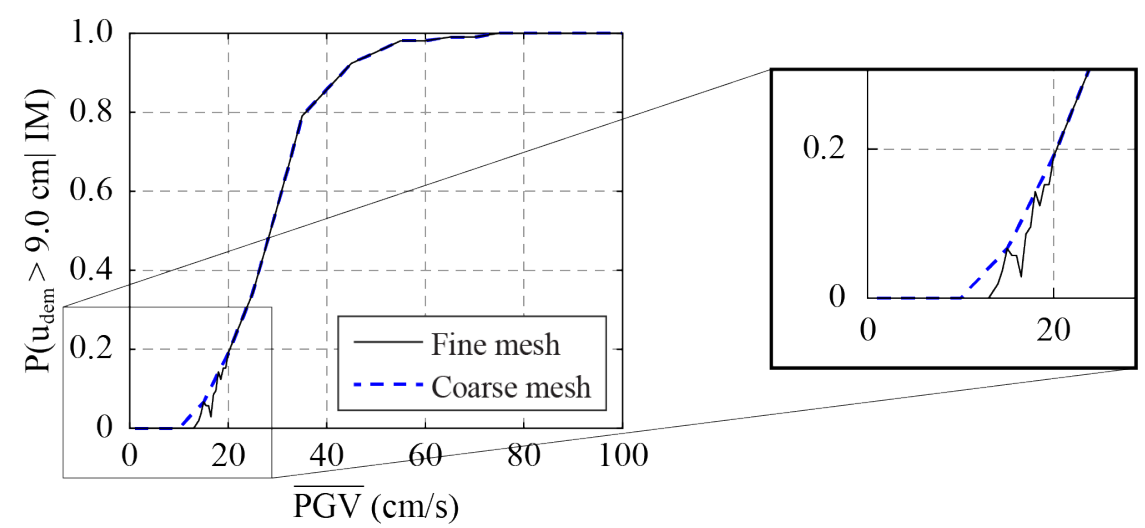

Figure 9. Fragility curves obtained for coarse and fine mesh.

\subsection{Uniform Risk Spectra}

Fig. 10 presents the uniform risk spectra for negative stiffness systems with $2 \%, 10 \%$, and $50 \%$ probability of exceedance in 50 years, for a site in Athens, Greece. These probabilities correspond to a MAF of $0.0004,0.0021$, and 0.0139 per year, as given by Eq. 9 , in which $p$ is the probability of exceedance and $T$, the number of years considered.

$$
\mathrm{MAF}=\frac{-\ln (1-p)}{T}
$$

It can be observed that the spectrum with smaller probability of exceedance $(2 \%$ in 50 years) predicts larger displacement demands, while the spectrum with larger probability of exceedance (50\% in 50 years) predicts smaller displacement demands.

The figure also depicts an interesting characteristic: if the curves were scaled by two distinct factors at $\mathrm{x}$ - and y-axes, they would collapse into a unique curve. This a very remarkable characteristic that might allow negative stiffness systems to be designed for different performance scenarios using a unique curve.

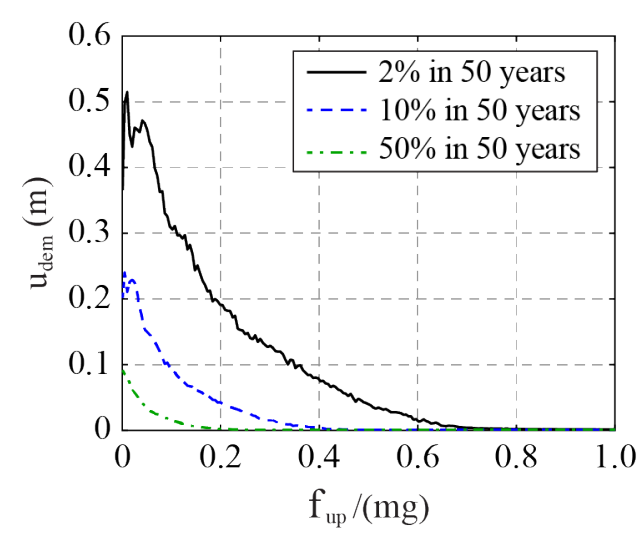

Figure 10. Uniform risk spectra for negative stiffness systems with $2 \%, 10 \%$, and $50 \%$ probability of exceedance in 50 years, for a site in Athens, Greece. 


\section{CONCLUSIONS}

This paper presented uniform risk spectra for negative stiffness systems, using the ZSBE proxy. It explains in detail the probabilistic framework necessary to construct such spectra, highlighting possible source of errors. It presents uniform risk spectra for three probabilities of exceedance: $2 \%, 10 \%$, and $50 \%$ in 50 years. The uniform risk spectrum, however, can be computed for any given MAF and site, following the framework presented herein.

Interestingly, it seems that the uniform risk spectra for different MAF can be scaled in the $\mathrm{x}$ - and $\mathrm{y}$-axes, collapsing to a unique curve. This characteristic would make the design of negative stiffness systems even simpler: one "master" curve could be use to design negative stiffness systems with different displacement capacities for different performance scenarios.

Further studies are still necessary on which is the adequate intensity measure to be adopted for these spectra.

\section{REFERENCES}

[1] N. Makris, M. Vassiliou. Planar rocking response and stability analysis of an array of free-standing columns capped with a freely supported rigid beam. Earthq. Eng. Struct. Dyn., 42, 431-449, 2013.

[2] N. Makris, M. F. Vassiliou. Are Some Top-Heavy Structures More Stable?. J. Struct. Eng., 140 (5), 06014001, 2014.

[3] N. Makris, M. F. Vassiliou. Dynamics of the Rocking Frame with Vertical Restrainers. J. Struct. Eng., 141 (10), 04014245, 2015.

[4] E. G. Dimitrakopoulos, A. I. Giouvanidis. Seismic Response Analysis of the Planar Rocking Frame. J. Eng. Mech., 141 (7), 04015003, 2015.

[5] M. F. Vassiliou, N. Makris. Dynamics of the Vertically Restrained Rocking Column. J. Eng. Mech., 141 (12), 04015049, 2015.

[6] A. I. Giouvanidis, E. G. Dimitrakopoulos. Seismic Performance of Rocking Frames with Flag-Shaped Hysteretic Behavior. J. Eng. Mech., 143 (5), 04017008, 2017.

[7] A. Agalianos, A. Psychari, M. F. Vassiliou, B. Stojadinovic, I. Anastasopoulos. Comparative assessment of two rocking isolation techniques for a motorway overpass bridge. Front. Built Environ., 3, 1-19, 2017.

[8] M. F. Vassiliou, K. R. Mackie, B. Stojadinovic. A finite element model for seismic response analysis of deformable rocking frames. Earthq. Eng. Struct. Dyn., 46 (3), 447-466, 2016.

[9] M. F. Vassiliou, S. Burger, M. Egger, J. A. Bachmann, M. Broccardo, B. Stojadinovic. The three-dimensional behavior of inverted pendulum cylindrical structures during earthquakes. Earthq. Eng. Struct. Dyn., 46 (14), 2261-2280, 2017.

[10] M. F. Vassiliou. Seismic response of a wobbling 3D frame. Earthq. Eng. Struct. Dyn., 47 (5), 1212-1228, 2018.

[11] A. Dar, D. Konstantinidis, W. El-Dakhakhni. Seismic response of rocking frames with top support eccentricity. Earthq. Eng. Struct. Dyn., 47 (12), 2496-2518, 2018.

[12] I. M. Thomaidis, A. J. Kappos, A. Camara. Dynamics and seismic performance of rocking bridges accounting for the abutment-backfill contribution. Earthq. Eng. Struct. Dyn., 49 (12), 1161-1179, 2020.

[13] R. Thiers-Moggia, C. Málaga-Chuquitaype. Seismic protection of rocking structures with inerters. Earthq. Eng. Struct. Dyn., 48 (5), 528-547, 2019.

[14] J. A. Bachmann, M. F. Vassiliou, B. Stojadinovic. Rolling and rocking of rigid 
uplifting structures. Earthq. Eng. Struct. Dyn., 48 (14), 1556-1574, 2019.

[15] J. A. Bachmann, M. F. Vassiliou, B. Stojadinovic. Dynamics of rocking podium structures. Earthq. Eng. Struct. Dyn., 46 (14), 2499-2517, 2017.

[16] G. Ríos-García, A. Benavent-Climent. New rocking column with control of negative stiffness displacement range and its application to RC frames. Eng. Struct., 206, 110133, 2020.

[17] M. Aghagholizadeh, N. Makris. Earthquake response analysis of yielding structures coupled with vertically restrained rocking walls. Earthq. Eng. Struct. Dyn., 47 (15), 2965-2984, 2018.

[18] M. Sieber, S. Klar, M. F. Vassiliou, I. Anastasopoulos. Robustness of simplified analysis methods for rocking structures on compliant soil. Earthq. Eng. Struct. Dyn., 49 (14), 1388-1405, 2020.

[19] Giouvanidis, A. I., \& Dong, Y. (2020). Seismic loss and resilience assessment of single-column rocking bridges. Bulletin of earthquake engineering, 18, 4481-4513.

[20] Y. L. Zhou, Q. Han, X. L. Du, J. Q. Zhang, S. S. Cheng, J. Y. Chen. Additional viscous dampers for double-column rocking bridge system: Seismic response and overturning analysis. Soil Dyn. Earthq. Eng., 141, 106504, 2021.

[21] Y.-L. Zhou, Q. Han, X.-L. Du, Z. Jia. Shaking Table Tests of Post-Tensioned Rocking Bridge with Double-Column Bents. J. Bridg. Eng., 24 (8), 04019080, 2019.

[22] Giouvanidis, A. I., \& Dimitrakopoulos, E. G. (2017). Seismic performance of rocking frames with flag-shaped hysteretic behavior. Journal of Engineering Mechanics, 143(5), 04017008 .

[23] N. Luco, B. R. Ellingwood, R. O. Hamburger, J. D. Hooper, J. K. Kimball, and C. A. Kircher. Risk-targeted versus current seismic design maps for the conterminous united states. Struct. Eng. Assoc. Calif. 2007 Conv. Proc., Squaw Creek, California, United States, September, 26-29, 2007.

[24] N. Makris, D. Konstantinidis. The rocking spectrum and the limitations of practical design methodologies. Earthq. Eng. Struct. Dyn., 32 (2), 265-289, 2003.

[25] N. Reggiani Manzo, M. F. Vassiliou. Displacement-based analysis and design of rocking structures. Earthq. Eng. Struct. Dyn., 48 (14), 1613-1629, 2019.

[26] N. Reggiani Manzo, M. F. Vassiliou. Simplified analysis of bilinear elastic systems exhibiting negative stiffness behavior. Earthq. Eng. Struct. Dyn., 50 (2), 580-600, 2021.

[27] S. Acikgoz, M. J. DeJong. The rocking response of large flexible structures to earthquakes. Bull. Earthq. Eng., 12 (2), 875-908, 2014.

[28] E. G. Dimitrakopoulos, T. S. Paraskeva. Dimensionless fragility curves for rocking response to near-fault excitations. Earthq. Eng. Struct. Dyn., 44 (12), 2015-2033, 2015.

[29] A. I. Giouvanidis, E. G. Dimitrakopoulos. Rocking amplification and strong-motion duration. Earthq. Eng. Struct. Dyn., 47 (10), 2094-2116, 2018.

[30] Y. Xie, J. Zhang, R. DesRoches, J. E. Padgett. Seismic fragilities of single-column highway bridges with rocking column-footing. Earthq. Eng. Struct. Dyn., 48 (7), 843864, 2019.

[31] M. Ebad Sichani, J. E. Padgett, V. Bisadi. Probabilistic seismic analysis of concrete dry cask structures. Struct. Saf., 73, 87-98, 2018.

[32] E. Bakhtiary, P. Gardoni. Probabilistic seismic demand model and fragility estimates for rocking symmetric blocks. Eng. Struct., 114, 25-34, 2016.

[33] B. Kafle, N. T. K. Lam, E. F. Gad, J. Wilson. Displacement controlled rocking behaviour of rigid objects. Earthq. Eng. Struct. Dyn., 40 (15), 1653-1669, 2011.

[34] H. Roh, G. P. Cimellaro. Seismic fragility evaluation of RC frame structures retrofitted 
with controlled concrete rocking column and damping technique. J. Earthq. Eng., 15 (7), 1069-1082, 2011.

[35] L. Deng, B. L. Kutter, S. K. Kunnath. Probabilistic Seismic Performance of RockingFoundation and Hinging-Column Bridges. Earthq. Spectra, 28 (4), 1423-1446, 2012.

[36] I. N. Psycharis, M. Fragiadakis, I. Stefanou. Seismic reliability assessment of classical columns subjected to near-fault ground motions. Earthq. Eng. Struct. Dyn., 42 (14), 2061-2079, 2013.

[37] K. Bakalis, A. K. Kazantzi, D. Vamvatsikos, M. Fragiadakis. Seismic Performance Evaluation of Liquid Storage Tanks Using Nonlinear Static Procedures. J. Press. Vessel Technol. Trans. ASME, 141 (1), 1-13, 2019.

[38] D. Kalliontzis, S. Sritharan, A. Schultz. Improved Coefficient of Restitution Estimation for Free Rocking Members. J. Struct. Eng., 142 (12), 06016002, 2016.

[39] C. A. Cornell, H. Krawinkler. Progress and challenges in seismic performance assessment. PEER Cent. News, 3 (2), 1-2, 2000.

[40] A. K. Kazantzi, D. Vamvatsikos. Intensity measure selection for vulnerability studies of building classes. Earthq. Eng. Struct. Dyn., 44 (15), 2677-2694, 2015.

[41] D. Vamvatsikos, C. A. Cornell. Incremental dynamic analysis. Earthq. Eng. Struct. Dyn., 31 (3), 491-514, 2002.

[42] Global Earthquake Model (GEM). OpenQuake Engine User Instruction Manual, 2016.

[43] J. Woessner, D. Laurentiu, D. Giardini et al., The 2013 European Seismic Hazard Model: key components and results. Bull. Earthquake Eng., 13, 3553-3596, 2015. 